\title{
Calcitonin Stimulates Glycogenolysis in the Liver of Fasted Rats
}

\author{
Masayoshi YAMAGUCHI \\ Department of Environmental Biochemistry, Shizuoka College of \\ Pharmacy, 2-2-1, Oshika, Shizuoka, 422
}

\begin{abstract}
The effect of calcitonin (CT) on glycogenolysis in the liver was investigated in fasted rats. The fasting produced a marked decrease in the hepatic glycogen content. Thyroparathyroidectomy (TPTX) significantly prevented the decline in hepatic glycogen by fasting as compared with sham operation. This prevention by TPTX was

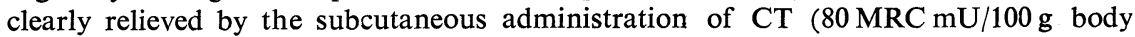
weight). The appreciable effect of the hormone was also observed at the dose of 20 and $40 \mathrm{MRC} \mathrm{mUCT} / 100 \mathrm{~g}$ body weight. The present results suggest that $\mathrm{CT}$ plays a physiological role in the stimulation of hepatic glycogenolysis after fasting in rats.
\end{abstract}

Calcitonin (CT), a calcium-regulating hormone, affects carbohydrate metabolism. CT increases the glucose concentration in the serum of fed and fasted rats, and this effect of CT is not mediated by hypocalcemia (Yamaguchi and Yamamoto, 1977). The hyperglycemic effect of CT also is not dependent on the releases of epinephrine from the adrenal glands (Yamaguchi, 1980) and glucagon from the pancreas (Yamaguchi, 1981). Thus, CT may have a stimulatory effect on glucose production in rats. The present study was therefore undertaken to investigate a physiological role of CT on hepatic glycogenolysis in fasted rats. It was found that CT stimulates hepatic glycogenolysis in fasted rats.

\section{Materials and Methods}

\section{Animals}

Male Wistar rats, weighing approximately $120 \mathrm{~g}$, were used in this experiment. The animals were fed commercial laboratory chow containing $57.4 \%$, $1.1 \% \mathrm{Ca}$ and $1.1 \% \mathrm{P}$ (Oriental Test Diet Co., Ltd., Tokyo, Japan) and tap water freely. The animals were fasted for $11 \mathrm{hr}$ from am 9 to pm 8 .

\section{Hormone}

Calcitonin (lyophylized porcine calcitonin, 68 MRC $\mathrm{U} / \mathrm{mg}$ protein, Armour Pharmaceutical Company, Kankakee, I11., U.S.A.) was dissolved in cold distilled water to concentrations of 20,40 and 80 MRC $\mathrm{mU} / 0.5 \mathrm{ml}$. These solutions $(0.5 \mathrm{ml} / 100 \mathrm{~g} \mathrm{BW})$ were subcutaneously administered 2 or 4 times at $1-\mathrm{hr}$ intervals from 2 p.m. in rats fasted from 9 a.m. The rats were sacrificed $1 \mathrm{hr}$ after the last administration of CT. The control injection consisted of distilled water.

\section{Surgical Procedures}

The thyroparathyroid gland complex was removed with fine forceps under light anesthesia with ether at midday. The sham-operated rats were not removed thyroparathyroid glands, although the neck was opened by a middle incision. 
Analytical Methods

Blocd was obtained by cardiac puncture. The amount of glucose in the serum was measured with the Glytel c-toluidine reagent (Hyvarimen and Nikkila, 1962). Liver was perfused with a cold $0.9 \%$ $\mathrm{NaCl}$ solution after bleeding and removed immediately. The liver was frozen rapidly. Liver glycogen was determined by a modification of the method of Good et al. (1933). The tissues were digested in $30 \% \mathrm{KOH}$ in a boiling water bath for $1.5 \mathrm{hr}$ and glyccgen was precipitated by adding $99.5 \%$ ethanol and allowirg the samples to stand overnight at $4{ }^{\circ} \mathrm{C}$. The samples were then centrifuged and the supernatant was decanted. Glycogen was then washed with $99.5 \%$ ethanol, hydrolyzed with $1 \mathrm{M} \mathrm{H}_{2} \mathrm{SO}_{4}$, and aliquots were analyzed for gluccse by using the Glytel reagent. The weight of glycogen is expressed as $\mathrm{mg}$ of gluccse per $\mathrm{g}$ wet liver tissue.

\section{Statistical Method}

The significance of differences bitween the values was estimated by Student's $t$-test. P values less than 0.05 were considered to indicate statistically significant differences.

\section{Results and Discussion}

Calcitonin (CT) increases the glucose concentration in the serum of fed and fasted rats (Yamaguchi and Yamamoto, 1977). However, it is uncertain whether CT plays a physiological role in the regulation of serum glucose level in rats. Accordingly a role of $\mathrm{CT}$ on glycogenolysis in the liver of fasted rats was investigated in shamoperated rats and thyroparathyroidectomized rats.

First, the changes in glucose concentration in the serum and glycogen content in the liver of rats fasted from am 9 to pm 8 were examined, and the results are shown in Fig. 1. The serum glucose concentration was not significantly decreased by fasting until p.m. 4 as compared with the value obtained at 9 p.m., although by 6 and 8 p.m. it was reduced to the values which were statistical significant. On the other hand, the hepatic glycogen content was markedly lowered by fasting. The glycogen content was significantly decreased

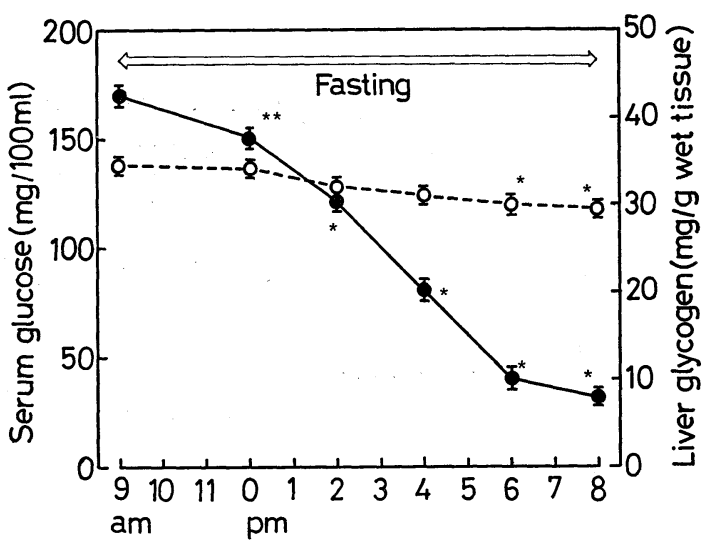

Fig. 1. Changes in gluccse concentration in the serum and glyccgen conten in the liver of fasted rats. Rats were fasted from 9 a.m. to 8 p.m. Each point represents the mean for 5 or 6 animals. Vertical lines represent the SE. *; $\mathrm{P}<0.01$ as compared with the value cbtained at 9 a.m. *** $; \mathbf{P}<0.05$ as compared with the value obtained at 9 a.m. -- $\mathrm{O}^{--}$; serum gluccse, - - ; hepatic glycogen.

by midday compared with the value obtained at am 9, and then it began to drop rapidly. Thus hepatic glycogenolysis plays a physiological role in maintaining homeostasis of the serum glucose level after fasting.

The effect of thyroparathyroidectomy on the reduction in glycogen content in the liver of rats fasted from am 9 is shown in Fig. 2. The rats were thyroparathyroidectomized at midday. The hepatic glycogen content in thyroparathyroidectomized rats increased significantly as compared with the values obtained from sham-operated rats at pm 2, 4 and 6, respectively. The result that thyroparathyroidectomy (TPTX) clearly prevented the decline of glycogen level in the liver by fasting suggests that thyroparathyroid glands may participate in the promotion of hepatic glycogenolysis after fasting.

The effect of CT ( $80 \mathrm{MRC} \mathrm{mU} / 100 \mathrm{~g}$ $\mathrm{BW}$ ) on the prevention of glycogenolysis 


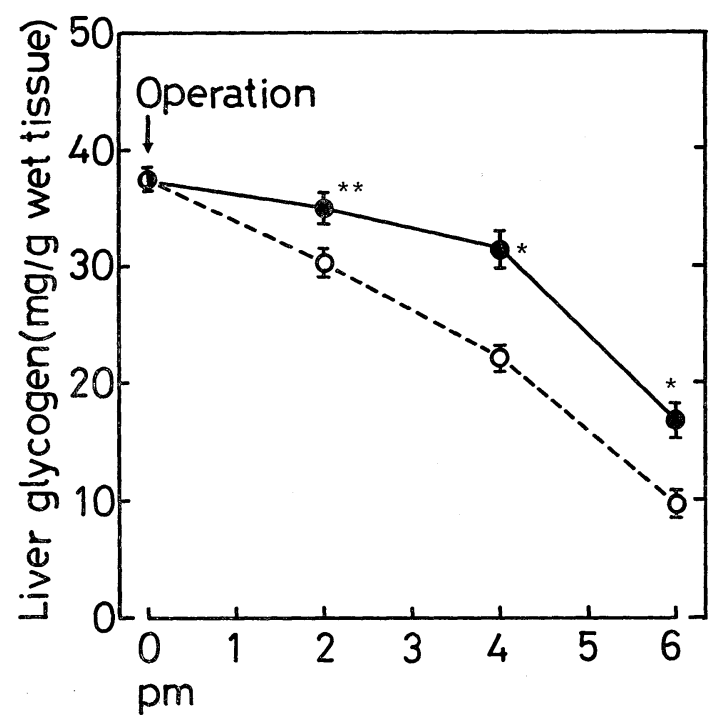

Fig. 2. Effect of thyroparathyroidectomy on the decline in glycogen content in the liver of fasted rats. Rats were fasted from 9 a.m., and they were thyroparathyroidectomized at midday. Each point represents the mean for 5 or 6 animals. Vertical lines represent the SE. *; $\mathrm{P}<0.01$ as compared with the value cbtained at 4 p.m. and 6 p.m. of sham-operated rats. **; $\mathrm{P}<0.05$ as compared with the value obtained at 2 p.m. of sham-cperated rats. -- $0_{--}$; sham-operated rats, - - ; thyroparathyroidectomized rats.

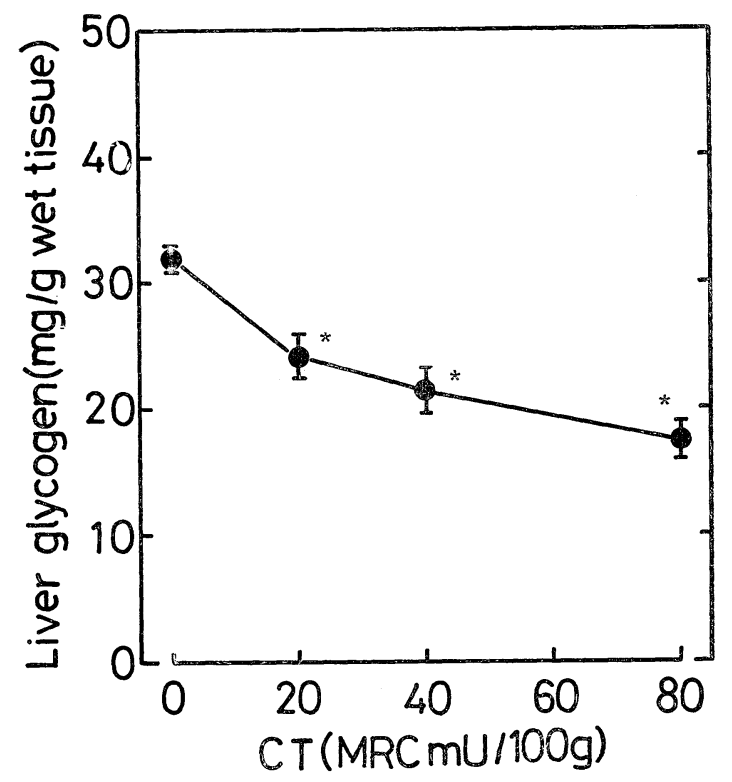

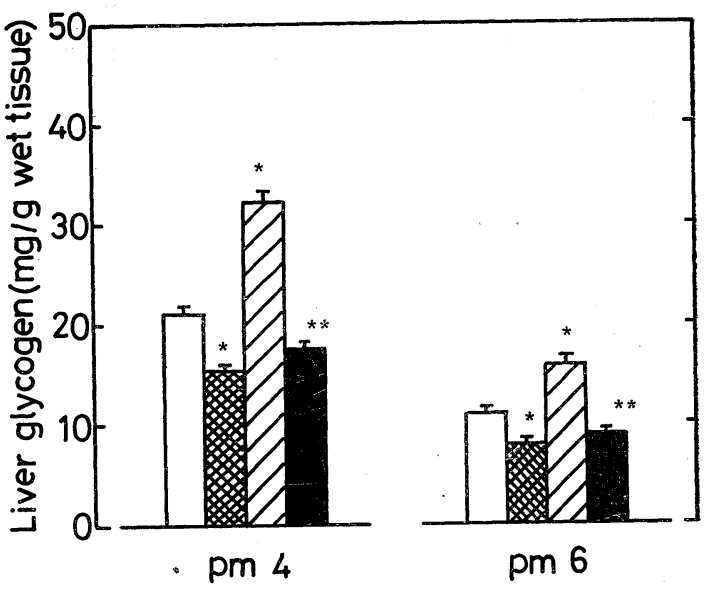

Fig. 3. Effect of calcitonin (CT) on glyccgen content in the liver after thyroparathyroidectomy in fasted rats. Rats were fasted from 9 a.m., and the animals were thyroparathyroidectomized at midday. The rats received the subcutaneous administration of CT ( $80 \mathrm{MRC} \mathrm{mU} / 100 \mathrm{~g} \mathrm{BW}$ ) 2 or 4 times at 1-hr intervals from pm 2, and they were sacrificed at 4 p.m. or 6 p.m. Each bar represents the mean of 6 or 7 animals. Vertical lines represent the SE. *; $\mathbf{P}<0.01$ as compared with the value of sham-operated rats. ${ }^{* *} ; \mathrm{P}<0.01$ as compared with the value of thyroparathyroidectomized rats. $\square$; sham-operated rats, sham-operated rats treated with CT, $\square$; thyroparathyroidectomized rats, ; thyroparathyroidectomized rats treated with $\mathrm{CT}$.

Fig. 4. Effect of increasing doses of calcitonin (CT) on glyccgen content in the liver after thyroparathyroidectomy in fasted rats. Rats were fasted from 9 a.m., and the animals were thyroparathyroidectomized at midday. The rats received the subcutaneous administration of CT (20,40 and $80 \mathrm{MRC} \mathrm{mU} / 100 \mathrm{~g} \mathrm{BW}) 2$ times at $1-\mathrm{hr}$ intervals from 2 p.m., and they were sacrificed at 4 p.m. Each point represents the mean for 5 or 7 animals. Vertical lines represent the SE. *; $\mathrm{P}<0.01$ as compared with the value of control thyroparathyroidectomized rats. 
in the liver by TPTX in fasted rats is shown in Fig. 3. In sham-operated rats, the administration of CT caused a significant decrease in the hepatic glycogen content compared with that of the control group at 4 and 6 p.m., respectively. On the other hand, the hepatic glycogen content increased by TPTX compared with the value obtained from sham-operated rats at both 4 and 6 p.m. was significantly reduced by the administration of CT. These results indicate that CT clearly relieved the preventive effect of TPTX on the drop in the hepatic glycogenolysis after fasting in rats.

The effect of increasing doses of CT $(20,40$ and $80 \mathrm{MRC} \mathrm{mU} / 100 \mathrm{~g} \mathrm{BW})$ on the prevention of glycogenolysis in the liver by TPTX in fasted rats is shown in Fig. 4. The hormone significantly relieved the preventive effect of TPTX on the decline in hepatic glycogen content by fasting even at the lowest dose (20 MRC mU/100 g BW). With higher doses, the effect was slightly greater, but the effect of $80 \mathrm{MRC} \mathrm{mU} / 100 \mathrm{~g}$ $\mathrm{BW}$ of CT was not significantly greater than that of $40 \mathrm{MRC} \mathrm{mU} / 100 \mathrm{~g} \mathrm{BW}$.

In conclusion, the present study suggests that CT stimulates glycogenolysis in the liver of fasted rats. The effect of CT may be an important action as a physiological role of the hormone in mammals.

\section{Acknowledgements}

This work was supported in part by a Grant-inAid (No. 577928) for Scientific Research from the Ministry of Education, Science and Culture, Japan.

\section{References}

Hyvarimen, A. and E. A. Nikkila (1962). Specific determination of blood glucose with o-tolnidine. Clin. Chim. Acta 7, 140-143.

Good, C. A., H. Kramer and M. Somogyi (1933). The determination of glycogen. J. Biol. Chem. 100, 485-491.

Yamaguchi, M. and T. Yamamoto (1977). Effect of calcitonin on serum glucose concentration in rats. Chem. Pharm. Bull. 25, 2189-2194.

Yamaguchi, M. (1980). Effects of calcitonin and epinephrine on serum glucose concentration in rats. Chem. Pharm. Bull. 28, 3693-3695.

Yamaguchi, M. (1981). Calcitonin increases serum glucose concentration independently of insulin secretion in rats. Chem. Pharm. Bull. 29, 14551458 . 